\title{
Conflict Resolution Styles of XI Grade students in Delhi: An Experimental Study
}

\author{
G. Shivani S. Ruchi \\ NCERT, Department of Educational Psychology and Foundations of Education, India
}

\begin{abstract}
The purpose of this study was to investigate the influence of interventions conducted to bring a positive change in conflict resolution styles among students of Class XI. Conflict resolution style was measured by Thomas- Kilmann Mode Instrument. Forty five students of Standard XI participated in the study. A pre-test and post-test experimental design was used. A pre-test was carried out in the beginning of the interventions to determine the conflict resolution style used by participants in their inter-personal conflicts. The interventions, in the form of group activities like removing the blocks in communication, effective usage of non-verbal communication, importance of listening, group discussion on anger management, and inculcation of constructive social skills were conducted. A post-test was carried out to measure the effects of interventions on participants' conflict resolution styles. Results indicated that the conflict resolution style of the group was modified and transformed into a mature and constructive way of dealing with conflicts.
\end{abstract}

Keywords: Conflict, Conflict Resolution, Conflict Resolution Styles, Communication.

DOI: $10.7176 / \mathrm{JEP} / 10-4-04$

\section{Introduction}

Society is the coming together of individuals who are governed by the same rules but nevertheless have varied backgrounds. The culture, family, education, gender and personal experiences etc. shape a person's outlook and perception towards things giving each individual a uniqueness. This uniqueness of each individual is as much a source of variety as it is for conflict. Conflicts are natural aspect of human interactions. They are universal although their nature and intensity may vary from person to person

Conflict is a process that starts when individuals or groups have differences and a serious incompatibility or disagreement regarding interests, beliefs, opinions, values, or practices (Mukhtar \& Habib, 2010). According to Oner (1996), "conflict generally happens when wants, needs, opinions and point of views of people counteract. Sometimes, the discourses and contrasting behaviours of the individuals are different from each other, or the individuals perceive the other person's demeanor in a different way, which leads to conflict". It is a common assumption that any kind of conflict is inherently bad but it is to be understood that it is not the conflict but the outcome or consequence of conflict that is good or bad, which in turn depends on how people express and deal with conflict.

Dealing with conflict constructively can lead to a variety of outcomes like bringing problems out in the open where they can be solved, putting an end to source of discontent and leading to new insights through expression of divergent views. However, not everyone reacts to conflicts in the same way. The way one responds to a conflict is generally intervened by factors like culture, gender, religion and individual differences. These differences alter the perception and intensity of the experienced conflict. Even ordinary conflict could escalate into a major one for some people. The habitual ways of responding to conflict gradually become relatively permanent style characterizing the individual. Learning to manage conflict is an essential skill in today's world.

Properly managed conflict can improve the interpersonal relationship and enhance positive behaviours in an individual. This strategy of managing conflict is formally known as Conflict Resolution. The way in which an individual approaches situations involving conflict is recognized as an individual's characteristic mode of resolving conflict (Moberg, 1998). Sweeney and Carruthers (1996) define conflict resolution (CR) as "the process used by parties in conflict to reach a settlement" (p. 328). Blake and Mouton were the first to analyze conflict resolution by stating that "individuals have two primary motivations with regard to interpersonal conflict: the desire to obtain one's own goals versus the desire to retain interpersonal relationships." Conflict resolution is a way for two or more parties to find a peaceful solution to a disagreement and conflict among them. Conflict Resolution involves the reduction, elimination, or termination of all forms and types of conflict.

Conflict resolution styles can be used to reduce and eliminate conflicts. A model called the "Thomas-Kilmann model" was designed by two psychologists, Kenneth Thomas and Ralph Kilmann. It demonstrates how individuals choose the conflict styles when they handle conflict. Thomas-Kilmann model suggests five conflict handling styles that guide individuals in the conflict process. These are competing, accommodating, avoiding, compromising, and collaborating.

- Competing means stand up for your own rights and defend what you believe is correct.

- Accommodating means that you yield to other's points of view.

- Collaborating means both sides are willing to cooperate and listen to others. 
- Compromising means both parties seek a better solution in the middle ground as one gives to another while one takes.

- Avoiding means an unassertive, uncooperative approach whereby a solution is delayed or avoided altogether. Both sides might wait until they would find a better solution or evade the situation.

Conflict resolution styles can empower an individual to resolve conflicts constructively. There is no right or wrong conflict resolution style, any individual in conflict is capable of choosing a style which seems more appropriate in accordance to the situation.

\section{Conflict amongst students}

Everyone faces conflict in their lives on a daily basis, even school students, especially adolescents are no exception when it comes to facing conflicts. Students from grade VIII to XII are in the transition period i.e. they are now moving from childhood to adolescence. This age group of 13 to 18 undergo certain changes and developments. In stages of development theory given by Erickson states that adolescence age is a stage of 'Identity vs Role Confusion'. An adolescent struggle to discover or find sense of self and his or her own identity. He/she also tries to develop a sense of morality and right from wrong. Kohlberg also stated in the 'Theory of moral development' that an adolescent begins to internalize the moral standards of a role adult model. An adolescent tries to focus on gaining approval from others. Thus, in this arbitrary stage, conflict need to arise. Conflicts among students can be because of many factors like, emergence of nuclear families, long working hours of both parents, less attention given to a child, advancement in technology and biological changes in students during adolescence. Adolescence is a crucial stage of discovery and dreams, along with it being a period of physical change, biological change and psychological change which may lead to confusions, tensions, frustrations and feelings of insecurity. Schools all over the world are grappling with aggression, violence and conflicts of various kinds among students. This violence and aggression leads to bullying, eve-teasing, a fight among students on discretion on moral values and selfidentity. These conflicts and unresolved problems engage the attention of the teachers, parents and school unproductively, these conflicts sometime grow in proportions to become violent taking on the lives of many students. Conflict is not always expressed violently, however it may express itself in the form of low achievement, strained interpersonal relationships and overall well-being of the individual.

It is important to understand the conflict resolution styles of adolescents in schools. Conflicts might escalate in adolescence age and could bring futility in an individual's life. There are lots of problems such as peer pressure, substance abuse, sexual harassment etc. increasing day by day on adolescents that we can see in newspapers every day. So there is a need to resolve effectively these conflicts in a fruitful way. This can be removed by the development of psychosocial maturity and giving training in resolving conflicts. An individual with conflict resolution management can lead a good life. The approach to conflict resolution management can lead to positive results in conflict. The conflicts may sometimes leads to better results and a final solution to problem. Though, conflict triggers strong emotions and lead to hurt feelings, disappointment and discomfort but when it is handled in a healthy manner it increases our understanding of one another, builds trust and strengthens our relationship bonds. When conflict is mismanaged, it can harm the relationship. But when handled in a respectful and in a positive way, conflict provides an opportunity for growth and ultimately strengthening the bond between two people or a group.

According to Blake and Mouton (1970), "When these basic styles are understood, one can predict for each how an individual operating under that style is likely to handle conflict." The conflict resolution styles adopted by adolescents predispose them to a number of maladaptive behaviors. Thus, there is a need for the identification of the nature of conflicts and the conflict resolution styles among students, and the factors that predispose adolescents to these styles. It will help to evolve intervention strategies to alter or modify the conflict resolution styles. The adolescents could be prepared for using cooperative and collaborative strategies of conflict resolution and problem solving.

\section{Education and Conflict Resolution}

An important concern of parents and teachers is to ensure holistic development of children in terms of their physical, intellectual and socio-emotional characteristics. One of the foremost goal of education is developing the capabilities of school going adolescents to living in harmony with themselves and others (National Curriculum Framework, 2005). Education shall empower an individual to choose peace as a way of life. Harmony in one's interpersonal relationships comes from the healthy attitudes, values, and skills which empower one to resolve conflict constructively.

Education helps to inculcate the skills in students to manage conflicts in an effective manner. Managing conflicts in a constructive manner is one of the most important skill that students need to master, which will lead to minimization of the occurrence of conflicts among students in schools and colleges (Johnson \& Johnson, 1996). Thus, training in conflict handling skills should be a combination of educational and recreational activities that are directed at improving individual skills in communicating with others, understanding the opinion and perception of 
others, looking at the situation from other person's point of view and conflict negotiation tactics that will assist the person in managing conflict (Fetherston, 1994; Wall \& Druckman, 2002). Training in conflict handling skills can provide the individual with an improved sense of control over the conflict and the ability to reach an amicable resolution. (Ramarajan at el, 2004).

Education is a significant dimension of the long-term process of building up peace, tolerance, intercultural understanding and civic responsibility for the future generations. Thus, there is a need to reorient education and the school curriculum shall take priority, to induct various educational, academic and recreational activities into the course content. Non-violent conflict resolution skills shall be nurtured and applied constructively to disputes between the individuals and groups. (National Curricular Framework, 2005). Education can make the students aware and recognize their own style of conflict resolution and would be able to comprehend with the best possible conflict resolution style for any situation. They can unravel the positive outcomes of conflicts. Thus, an awareness of the nature of the conflict helps a person appreciate the variety of ways that people can manage or respond to conflict. By learning a range of conflict resolution styles (such as competing, collaborating, accommodating, avoiding and compromising) will accommodate an individual to use these styles in an effective manner. Thus, in today's society, there is prerequisite to foster and stimulate a pragmatic and optimistic outlook towards conflict. Conflict education usually includes understanding the causes of conflict, the role of conflict in relationships, and the inevitable choices that conflict presents. Finally, conflict education should strengthen a person's capacity to create alternative solutions in response to problems. By cooperatively identifying problems and their solutions, children can develop skills to succeed in the classroom and beyond.

According to Johnson(1981), positive aspects of conflicts are; it helps the individual in knowing themselves, enhancing their awareness about others' characteristics, noticing the relationship problems that they need to solve, and encouraging change, increases energy and motivation for problem solving, making life more interesting, and help find small problems that are perceived as big issues. A positive conflict, can induce constructive results both for the conflicting person, and the person or the group that conflict is about. Johnson and Johnson (1995), found that "conflict can increase achievement, motivation to learn, higher-level reasoning, long term retention, healthy social and cognitive development, and the fun students have in school. Conflict can also enrich relationships, clarify personal identity, increase ego strength, promote resilience in the face of adversity, and clarify how one needs to change." When a step is taken towards a positive approach to handle conflicts, it may lead to increase in improved quality of decisions, arouse creativity and imagination, reinforcement of movement towards goals of an individual, fosters new ideas, alternative and solution towards the problem of the conflict.

\section{Objectives of the study}

1. To study the conflict resolution styles amongst students of class XI

2. To see the gender differences in the conflict resolution style amongst students of class XI

3. To see the effect of interventions on the conflict resolution styles amongst students of class XI.

\section{Methodology}

Sampling

This study was done using a pre and post-test experimental design on a sample of 45 male and female students of standard XI of a School in Delhi.

The pre-test was carried out in the beginning of the intervention to determine its impact on the conflict resolution styles that the participants use in their interpersonal conflicts. Then, intervention were introduced for three months to the group. The interventions were group activities like talks on the importance of listening, effective usage of non-verbal communication, removing the blocks in communication, significance of assertive communication, also a group discussion on anger management, and inculcation of constructive social skills were conducted. A focus on self-awareness and nurturing self-development was emphasized. Peer counselling was also introduced and initiated. Then a post-test administration of the tool was carried out to measure the effects of the interventions on participant's conflict resolution styles.

\section{Tool}

The data was collected by using the Thomas- Kilmann Conflict MODE Instrument to measure conflict handling styles of students. Year and the fact that it is standardised and used by researchers across the world. This instrument has two dimensions- assertiveness and cooperativeness in assessing conflicts. Assertiveness attempts to satisfy one's own concerns, while cooperativeness attempts to satisfy the concerns of others. There are five modes which are located on the assertiveness and cooperativeness axis. These five modes/styles of managing conflict are defined in the tool are as follows:

1. Collaborating: In this mode, people are both assertive and cooperative. Try to solve the problem mutually looking to satisfy the interest of both parties.

2. Compromising: Individuals using this mode are intermediate in both assertiveness and cooperation. They try to 
satisfy some goals of each party.

3. Competing: People using this mode are assertive and uncooperative. They try to fulfil their own interest.

4. Accommodating: Individuals using this mode are unassertive and cooperative. These people try to satisfy other's goals and set aside their own interest.

5. Avoiding: In this mode, people are unassertive and uncooperative. They usually postpone or avoid the issue. This instrument consists of 30 statements. Participants were requested to choose the response that describes the way one usually behave in conflicting situations.

\section{Discussion}

This study examined the effects of interventions on conflict resolution skills on students. The results of the test (Thomas Kilmann conflict mode instrument) conducted on participants showed a significant change in the conflict resolution styles of the students.

Table 1: Showing the Conflict Resolution Styles used by students of Grade XI.

\begin{tabular}{|l|l|l|l|l|l|}
\hline $\begin{array}{l}\text { Conflict Resolution } \\
\text { Styles }\end{array}$ & Collaborating & Competing & Avoiding & Accommodating & Compromising \\
\hline Before the intervention & 308 & 258 & 322 & 351 & 303 \\
\hline After the intervention & 367 & 240 & 293 & 354 & 371 \\
\hline
\end{tabular}

The findings of the study in table 1, show that students of Grade XI used the CRS of Accommodation most frequently. After the interventions conducted in three months, the conflict resolution style of the group was modified to Compromising which is a betterlmature style of dealing with conflicts. A change in conflict resolution style can be seen. This change is in a positive direction. In the CRS accommodating, an individual satisfy other people's goals, setting aside his/her own needs whereas Compromise style tries to satisfy some needs of both the parties.

Table 2: Showing the Conflict Resolution Styles used by girls.

\begin{tabular}{|l|l|l|l|l|l|}
\hline Conflict Resolution Styles & Collaborating & Competing & Avoiding & Accommodating & Compromising \\
\hline Before the intervention & 149 & 91 & 136 & 174 & 139 \\
\hline After the intervention & 169 & 98 & 122 & 165 & 156 \\
\hline
\end{tabular}

Table 3: Showing the Conflict Resolution Styles used by boys.

\begin{tabular}{|l|l|l|l|l|l|}
\hline Conflict Resolution Styles & Collaborating & Competing & Avoiding & Accommodating & Compromising \\
\hline Before intervention & 159 & 167 & 186 & 178 & 164 \\
\hline After the intervention & 198 & 142 & 171 & 190 & 208 \\
\hline
\end{tabular}

The findings of the study in table 2, show that Accommodating CRS was being used by the girls of Grade XI in the before interventions. After the activities conducted during intervention, the CRS of girls came out to be Collaborating. Individuals who use the CRS Accommodating are generally cooperative and unassertive. They try to fulfil other's goal and set aside their own interest. Whereas, the individuals who use Collaboration as their CRS are cooperative and assertive. They try to solve the problem mutually and satisfy the interest of both the parties. The results of the study show that the CRS of girls has been enhanced in a positive direction.

The study shows the CRS used by boys of Grade XI in Table 3. Before the interventions, the CRS of boys was Avoiding. After the activities conducted during intervention, the CRS of boys was Compromising. By using Avoiding CRS, people generally delay or postpone the issue. They do not generally want to find out the solution of the problem immediately. In Compromising CRS, individuals try to find out the solution of the issue to satisfy some of the needs of both the parties.

Learning to manage and resolve conflicts is an important part of becoming a productive member of society. This study focused on a productive change in the CRS of Grade XI students. The CRS of the students under intervention changed their Accommodating style to Compromising style. A study done by Laursen (1993) found that the adolescents generally use the strategies of accommodating and avoiding more often and compromising strategy less often. The study also found that they use compromising in many situations and also with their friends and family, and avoiding strategy scarcely with their close friends. In another study, Laursen, Hartuh, Koplas (1996) found that teenagers use compromising more with their friends, and relationships with peers, they use less forcing (Competing) with the peers who are just acquaints or not too close to them.

Several reasons can be attributed to the results of the study. First, in the three months intervention period the participants were able to do certain activities which have led to change in their perception and skill to resolve conflict. Secondly, a need assessment was conducted about the environment of the school and perception of the students prior the administration of study. The activities were planned according to the needs of the participants. The activities like importance of listening, effective usage of non-verbal communication, removing the blocks of communication, significance of assertive communication, a group discussion on anger management, and inculcation of constructive social skills in students might have helped them to know a positive meaning of the word conflict and have vigilant selection of conflict resolution style in day to day life. These activities were done 
with a focus on self-awareness and nurturing and enhancing the abilities of negotiation, dialogue and debate amongst the students was emphasized. During the intervention activities, it was observed that several students had no positive perception about themselves. They often stated 'I do not have any good quality.' It was therefore felt that an intervention needs to be made to lift their sense of self. With this in view a group activity of positive Qualities i.e. listing their own strengths, SWOT Analysis, Sentence completion activity on self-concept and the activity 'Gift from heart' i.e. students in a group of four gave 3 thoughts gifts to their friends to improve the selfesteem of students. The students showed improvement in the perception of their selves. Therefore, the selfawareness of students was elevated and self-esteem was restored.

Conflict resolution curricula and programs shall be provided at school level. It would provide opportunities for learners to apply skills in a variety of settings and enable them to adopt appropriate resolution style. This embedded curricula will enable the learners to appreciate the value of the acquired conflict resolution skills. Programs and activities addressing conflict resolution should be integrated into classrooms and schools as a whole. The goals of conflict resolution training should be to change students' mental and emotional prospective towards conflict and foster education and techniques that would help them to deal with daily challenges when confronted with conflicts. It appears that training related to conflict resolution needs to be planned for various levels of competence, for it to be effective at every level of school. Positive conflict resolution is a skill learned only through training and practice which need to be taught experientially. Experiential learning occurs when there are changes in judgments, feelings, perception, decision making, knowledge or skills that result from involvement in an activity or event over a period of time.

Men and women tend to uphold conflict behaviours that "complement gender role expectations". The findings stated that as opposed to girls' tendency towards searching for a solution, boys take the charge and try to command and influence the decision in their favour. In this study, it was observed that there is a difference of having a particular conflict resolution style among genders. Girls of the group are more inclined towards Accommodating style in the beginning of the interventions and changed into Collaborating after the interventions. On the other hands, boys were having an Avoiding style and after intervention the style changed into Compromising. One's orientation towards conflict has a direct correlation to how it is handled and about its general outcome. An individual's orientations towards conflict gives him/her a sense of what conflict entails, enables one to unfold, and identifies the process of seeking a resolution. The inclination of an individual towards a conflict resolution style might be because of his/her experiences in childhood and also due to emergence of nuclear families and long working hours of both the parents. The ideology and rationale thinking of families might affect the choice of conflict resolution style of an individual. In some of the patriarchy societies, it has been assumed and imposed on individuals, some unseen and invisible line of thoughts. Thus, it seems that there is a need to liberate the clutched hypothesis and presumptions of society.

Conflict between students and unhealthy relationship at schools can only be prevented by providing conflict resolution strategies programs. Students who efficaciously participated in the sessions or activities done in intervention, seemed to be more positive about their ability to create change for themselves and the world around them. At the heart of every conflict, can be misunderstandings, differing perceptions, wants and needs, and therefore conflict, if seen from a different perspective, can be an opportunity for growth and problem solving among all those who are concerned with it. The conflict resolution strategies and communication skills that students will learn, will give them peace, success and happiness within the society and among their peer groups. It will be productive for them, as they will be learning to use, collaborating and compromising strategies instead of destructive resolution strategies. To eliminate disciplinary events, the main target of the conflict resolution training programs should be to make the students learn to take responsibility for the resolution of their conflicts.

At the end of the programme, in which students are trained for conflict resolution strategies, the following acquisitions should be achieved

a) Improvement of skill of differentiating emotions from thoughts

b)Improvement of effective listening and communication skills

c) Development of empathetic skills

d)Development of social skills

e) To use the learned skills in social and future life.

f) To develop a skill to see conflict as an opportunity to develop oneself in a positive manner.

\section{References}

Blake, R., \& Mouton J. S., (1970). The fifth achievement. Journal of Applied Behavioural Science, 6, 413-426.

Carlisle, M. (2011). Healthy Relationships and Building Developmental Assets. Canadian Journal of Education, 34(3), pp. 18-32.

Carruthers, W.L., Carruthers, B. J.B., Day-Wines, N.L., Bostick, S., \& Waston, D.C. (1996). Conflict Resolution as Curriculum: A Definition, Description, and Process for Integration in Core Curricula. The School Counselor, 43(5), pp. 345-373. 
Cutrona, C., \& Guerin, D. (1994). Confronting Conflict Peacefully: Peer Meditation in Schools. Educational Horizons, 72(2), 95-104, The Challenges of Discipline: From Violence to Conflict Resolution (1994), pp. $95-$ 104.

Deen, M.Y. (2000). Difference in the solution-oriented conflict style of selected groups of 4-H youth development volunteer leaders. Journal of Extension, 38(1).

Din S., Khan B., Rehman R., \& Bibi Z. (2011). An investigation of conflict management in public and private universities: African Journal of Business Management Vol. 5(16), pp. 6981-6990. Retrieved from https://www.academicjournals.org

Dincyurek, S., \& Civelek, A.H. The Determination of the Conflict Resolution Strategies of University Students That They Use When They Have Conflicts With People. The Behaviour Analyst Today 9 (9.3\&9.4).

Fathima Jaseena, M.P.M., \& Divya, P., (2014). Psychological maturity and conflict resolution management of higher secondary school students.

Fetherston, A. B. (194). Towards a theory of United Nations peacekeeping. New York: St. Martin's Press.

Gibbons, K., (2010). Circle Justice: A Creative Arts Approach to Conflict Resolution in the Classroom: An Art Therapy. Journal of American Art Therapy Association, 27(2) pp. 84-89.

Johnson, D.W., (1981). Reaching out Interpersonal Effectiveness and Self Actualization.

Johnson, D.W., \& Johnson, R.T. (1996). Conflict Resolution and Peer Meditation Programs in Elementary and Secondary Schools: A Review of the Research. Review of Research of Educational Research, 66(4), 459-506. Retrieved from https://www.jstor.org

Johnson, D., Johnson, R., Dudley, B., Ward, M., \& Magnuson, D. (1995). The Impact of Peer Meditation Training on the Management of School and Home Conflicts. American Educational Research Journal Winter 1995, 32(4), 829-844. Retrieved from https://www.jstor.org.

Johnson, D.W., Johnson, R., Dudley, B., Mitchell, J., \& Fredrickson, J. (1997). The Impact of Conflict Resolution training on Middle School Students. Journal of Social Psychology, 137(1), 11-21.

Laursen, B. (1993). Conflict Management Among Close Friends, in B. Laursen (Ed.), Close Friendship in Adolescence: New Directions for Child Development, 39-59. San Francisco: Jossey- Bass.

Laursen, B., Hartup, W.W., and Koplas, A.L. (1996). Towards Understanding Peer Conflict, Merrill-Palmer Quaterly, 42, 1, 76-102.

Lindt, S. (2006). Six steps to Conflict Resolution. National Middle School Association: Middle Ground, 9(4), 33.

Lung, A.Y. (1999). Parent-Adolescent Conflict and Resolution in Chinese American and Caucasian Families. Digital Dissertations, AAAT 9939053.

Mills, J., \& Chusmir, L.H. (1988). Managerial Conflict Resolution Styles: Work and Home Differences. In Goldsmith, E. (Ed.), Work and Family: Theory, research, and applications (special issue). Journal of Social Behaviour and Personality, 3(4), 303-316.

Mukhtar, S. \& Habib, M.N. (2010). Private sector managers approach to conflict management: A study of relationships between conflict management styles and personality type. Journal of Contemporary Research Business, 2(1), 304-312.

Ohio State Dept. of Education, Columbus, Let's Resolve Conflicts Together: High School Classroom Activities. Conflict Management Week, May 1-7, 2000.

Pollan, S. \& Wilson-Younger, D. Conflict Resolution, Can it really make a difference in the classroom: Conflict Resolution Strategies for Classroom Teachers. Alcorn State University.

Rubin, J. Z., \& Brown, B. R. (1975). The social psychology of bargaining and negotiation. New York: Academic Press.

Samantara, R. (2004). Conflict Management Strategies and Organisational Effectiveness. Indian Journal of Industrial Relations, 39 (3), pp. 298-323.

Schellenberg, R. C., Savage, A. P., \& Refuss M. (2007). Reducing Levels of Elementary School Violence from Peer Meditation. Professional School Counseling, 10 (5), pp. 475-481.

Schulman, J. L., Ford, R. C., Bush, P.L., \& Kasper, J. C. (1973). Mental health in the Schools. The Elementary School Journal, 74 (1), pp. 48-56. The University of Chicago Press.

Soner Dogan Education Faculty, Cumhuriyet University, Sivas, Turkey. Conflicts Management Model in School: A mixed Design Study. Journal of Educational and Learning; 5(2); 2016

Spyridon, L. (2008). Conflict Management Styles and the Gender.

Sweeney, B., Caruthers, W.L. (1996). Conflict Resolution: History, philosophy, theory, and educational applications. School Counselor, 43(5), 326-344.

Tastan, N. (2006). Conflict Resolution Training and peer Meditations: Applied group counseling programs series.

Thompson., G. L. (2009). Language use in the Classroom: Understanding the Relationship between Perceptions, Beliefs, and Verbal Communication. Hispania, 92(3), pp. 537-549.

Ting-Toomey, S. (1986). Conflict communication styles in black and white subjective cultures. In: Kim, Young 
Yun, ed. Interethnic communication: Current research. Newbury Park, CA: Sage Publications.

Wachter, R.M. (1999). The effect of gender and communication mode on conflict resolution. Computers in Human Behavior, 15, 763-782.

Waithaka, G. A., Moore, S., \& Gitimu, N.P. (2015). Influence of conflict resolution training on conflict handling styles of college students. Research in Higher Education Journal Volume 28.

Wall, J., \& Druckman, D. (2002, June). Meditation in peacekeeping missions. Paper presented at the international Association for Conflict Management Conference, Park City, UT.

Weist, M.D., Lindsey, M., Moore, E., \& Slade, E. (2012). Building Capacity in School Mental Health. International Journal of Mental Health Promotion.

Weitzman, P.F., \& Weitzman, E. A. (2006). Brief Report: Promoting post formal thinking on the job: A protocol for interpersonal conflict resolution training. Journal of Adult Development, 13, 45-51.

Yavuzer, Y. (2012). Effect of creative drama-based group guidance on male adolescents' conflict resolution skills. Eurasian Journal of Educational Research, 47, 113-130. 